\title{
URBAN GREEN INFRASTRUCTURE FOR CLIMATE RESILIENCE: A REVIEW
}

\author{
Fahmyddin A'raaf Tauhid ${ }^{* 1}$ \\ Dept. of Architecture, Alauddin State Islamic University, Makassar \\ e-mail: ${ }^{* 1}$ fahmyddin.tauhid@uin-alauddin.ac.id
}

\begin{abstract}
As the climate change affectingon coastal cities by increasing the intensity and frequency of climate related disasters such as flooding, sea level rise, drought etc., the need to explore other urban infrastructure strategies than conventional one is required. This alternative not only mitigate the impacts but also improve the urban climate resilience. In line with it, green infrastructure/GI can be sustainable alternative in that way combine with gray infrastructure. Therefore, this paper reviews the concept of GI to advance the urban resilience associated with climate related disasters. Some strategies based on the current literature and projects are also recommended including managing flood risk, building resiliency to drought, reducing the urban heat island effect, lowering building energy demands, improving coastal resiliency, and reducing energy needed to manage water.
\end{abstract}

Key words: Green Infrastructure; Climate Resilience; Urban Resilience; Sustainability; Flood; Drought,Sea level Rise. 


\section{INTRODUCTION}

Disaster losses and damages in the global cities shows the trend at unsustainable path(Emmanuel et al. 2017). The development of cities by conversion land, modifying floodplain areas; the sea level rise; and rapid urbanization are other factors that undermining the urban resilience (Matthews 2015). This condition is worsened by the low capacity of city government to manage (Pelling 2003). Climate resilience is a global urban issue as the impacts are growing to people lives particularly in coastal areas. The growing intensity and impact of climate related disasters have made the city governments to more aware to improve such resilience including immense development of grey infrastructure.

However, despite a number of benefits, the introduction and development of green infrastructure/GI have a little attention within urban infrastructure development. Thus, this paper discusses the concept of GI to improve the urban resilience associated with climate related disasters. It also recommends GI's strategies to be used at any scales for delivering the benefits to urban development based on the current literature and projects. These recommendations comprise managing flood risk, building resiliency to drought, reducing the urban heat island effect, lowering building energy demands, improving coastal resiliency, and reducing energy needed to manage water.

\section{A. Urban Green Infrastructure And Sustainability}

Green infrastructure (GI) can be defined as the development of interconnected network of green space such as parks, greenways, retention ponds to deliver an ecosystem services for benefiting of urban community that associated with social, economic and environment(US Environmental Protection Agency 2010)(Fig.1). According to United States Environmental Protection Agency (2019), GI provides services to improve water quality and quantity, air quality, climate resiliency, habitat and wildlife connectivity as well as benefiting communities by green jobs opportunities, health aspect, providing recreation space and improving property values. The connectedness and incorporation of pre-existing natural and gray infrastructure may secure the success of GI objectives.

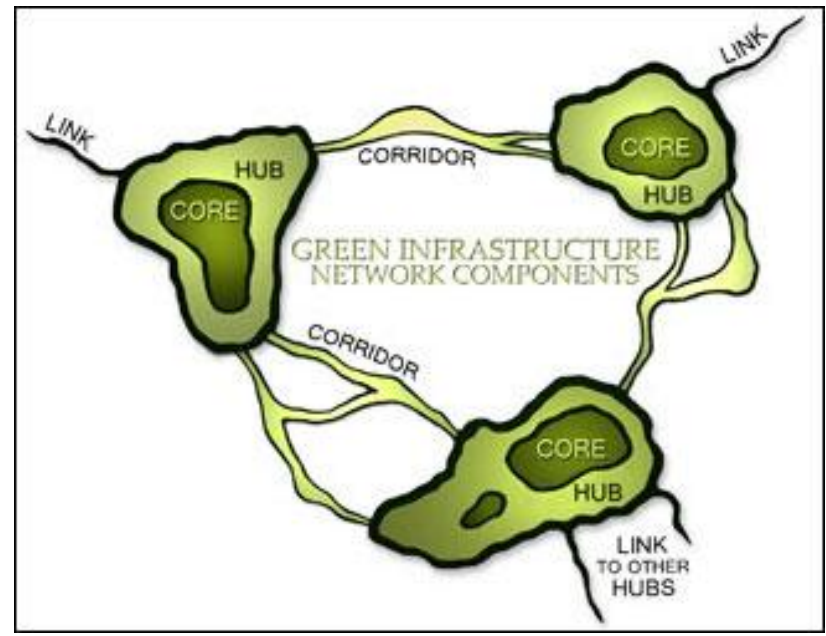

Fig 1. Green Infrastructure Networking 
GI can be formed at regional, city, neighborhood and site scale. At regional scale, GI is the element network of land conservation and ecological corridor. At urban scale, GI is made up of the urban forest/ tree canopy, urban parks, parkways and boulevards. At neighborhood scale GI includes the element of local parks, constructed wetlands, and green streets while at site scale it is composed of stormwater planters, rain gardens, green roofs and living walls (Mark 2006)(fig.2). Principally, GI elements are aimed to maintain natural hydrology functions by absorbing, infiltrating, and storing systems.

The increased temperature and change precipitation pattern have greatly impacted the community in cities as the intensity and frequency of climate related disasters like flooding or drought frequently occurring (Yosef 2013). This has increased the vulnerability that strongly link to reduce the urban resilience. It is the fact that city governments globally favor the development of gray infrastructure that is mainly intended to move stormwater away from cities, while green infrastructure lessens and treats it at its source. Introducing green infrastructure to complement the existing gray infrastructure can encourage urban livability for communities' resilience. For example, GI can mitigate the flooding by decreasing surface runoff and increasing storage capacity with more effective cost at 15\%- 64\% compare that grey infrastructure (Gill 2007). At site scale, green roofs method can decrease the runoff between 65-85 \% (Mentens et al. 2006). With this in mind, GI can provide a sustainability while enhance urban resilience to cope with climate related disasters.

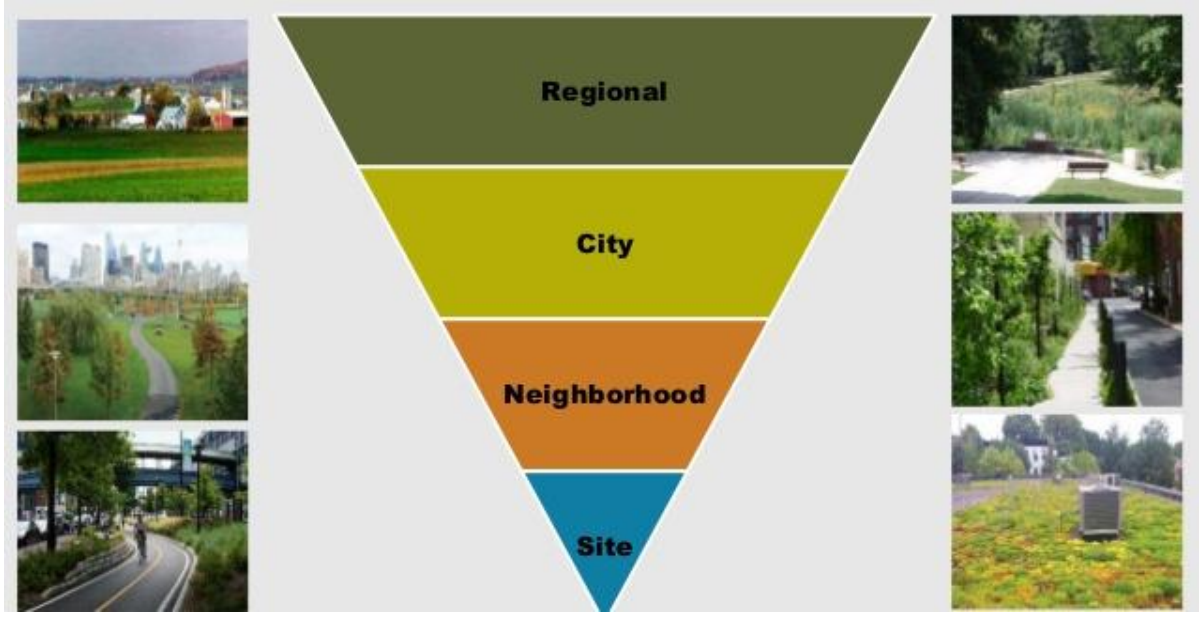

Fig 2. Green Infrastructure at any scales and forms

(Sources: The Conservation Fund1999)

\section{B. Green Infrastructure and Urban Climate Resilience}

Cities across the world already are experiencing the effects of climate change. In urban areas, such effects comprise increasing in temperature, heat waves and exacerbation of the heat island effect, change of the variability of precipitation with higher occurrence of high precipitation and flood events (IPCC2012), decreasing of quantity and quality of water resources, and loss of biodiversity and degradation of the landscape's aesthetic and recreational amenities (IPCC2014). There is a growing concern to address the consequences of climate change by city government and communities through adopting policies, planning and design aiming to strengthen the urban resilience in the face of climate disasters or a gradually changing climate.

According to UNISDR (2009), disaster resilience can be defined as 'the capacity of a system, community or society potentially exposed to hazards to adapt, by resisting or changing in order to reach and maintain an acceptable level of functioning and structure'. It can be said that GI can contribute in advancing socio, economic and environmental potential to improve 
the capacity of urban community. It can be one factor to determine to which individuals, communities and city government are capable to adapt with climate related disasters.

This study argues that adoption of GI in the urban policies can support disaster resilience as "an process". According to Manyena (2006), disaster resilience as "a process" is the supporting of the capacity of individuals, communities and governments to adapt through assets and resources relevant to their context. In line with this context, this study recommends GI's strategies that can improve and strengthen the urban climate resilience including managing flood risk, building resiliency to drought, reducing the urban heat island effect, lowering building energy demands, improving coastal resiliency, and reducing energy needed to manage water.

\section{Green Infrastructure to Improve Climate Resiliency}

The employment of GI benefitting cities is evident and become common practices especially at community scale. In the following, this study explores the use of green infrastructure approaches to incorporate with climate resilience at various scales;

1. Managing flood risk

As the temperatures continue to rise, the high intensity storms have been a frequent phenomenon(Trenberth2011). It significantly increases the vulnerability of cities to have flooding. GI can support manage both localized and riverine floods by absorbing excessive rainfall, preventing water from overwhelming gray infrastructure and pooling in open areas such as streets (fig.3). GI also can complement gray infrastructure by lessening the volume of stormwater that flows into streams and rivers, protecting floodplain functions and reducing infrastructure and property damage. For instance, GI elements that can improve infiltration comprise rain gardens, bioswales, and permeable pavements.

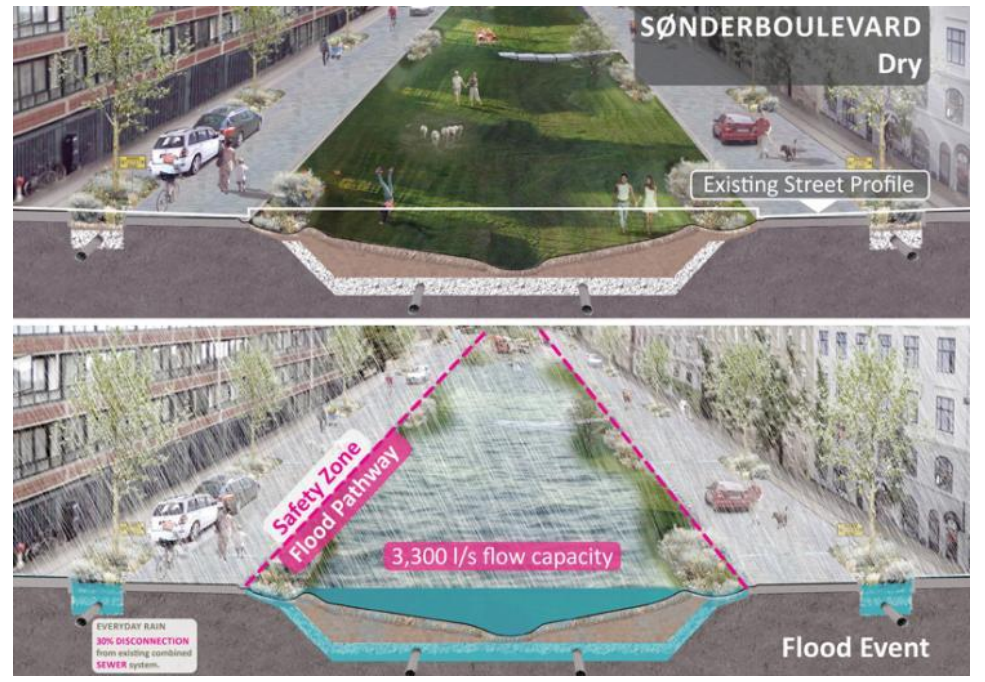

Fig 3. Copenhagen Cloudburst project for urban resilience using GI for managing flood risk (Sources: www.ramboll.com)

2. Building resiliency to drought

Many cities are experiencing the water shortage caused by decreased precipitation associated with climate change (Pielke 2013). The conventional grey infrastructure aims to channelized stormwater and push away from cities into water bodies. This method causes urban community losing such valuable water that could be used or stored for use when it is needed in drought time. GI approach can support refilling groundwater reserves, relieving 
water supplies stress for cities and decreasing the need to import potable water. For example, at local scale, rainwater harvesting systems can gather and store rainfall for later use (fig.4). It can also slow and reduce runoff. DEP's Rain Barrel Giveaway program as the part of New York City's Green Infrastructure Plan have adopted rainwater system by capturing stormwater before it flows to the sewer system and thereby reduce the flooding vulnerability(NYC Environmental Protection 2018).

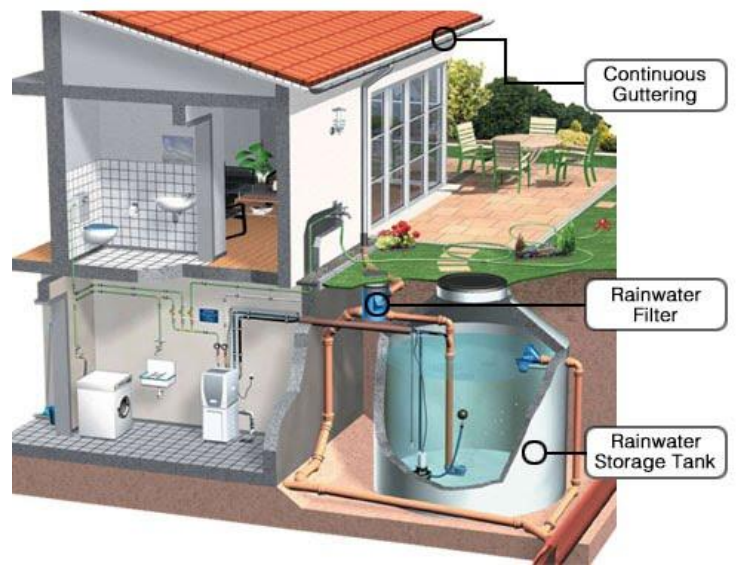

Fig 4. Rainwater harvesting system (Sources: Namitaveera)

3. Reducing the urban heat island effect

The conversion of natural land cover with dense concentrations of buildings, pavements, streets, and other surfaces that absorb and retain heat is the main cause of urban heat effect (Rajashree 2018) (fig.5). It increases the local temperature that lead to rising of energy costs to cooling, air pollution, and other health issues on urban communities. The urban heat effect also may trigger the longer heat waves in the summer months particularly in north global cities (Klok et al. 2018). A use of GI element such as trees, green roofs, green wall, and vegetation is expected to reduce urban heat island consequences by shading building surfaces, deflecting solar radiation, and releasing moisture into the atmosphere (Rajashree 2018). One of the accomplishment program is the green roof rebate program in 2006. Department of Energy \& Environment/ DOEE, DC under this program promotes the voluntary installation of green roofs to reducing stormwater runoff, pollutants and urban heat effect. DOEE offers a rebate of $\$ 10$ - $\$ 15$ per square foot for voluntary installations of green roofs.

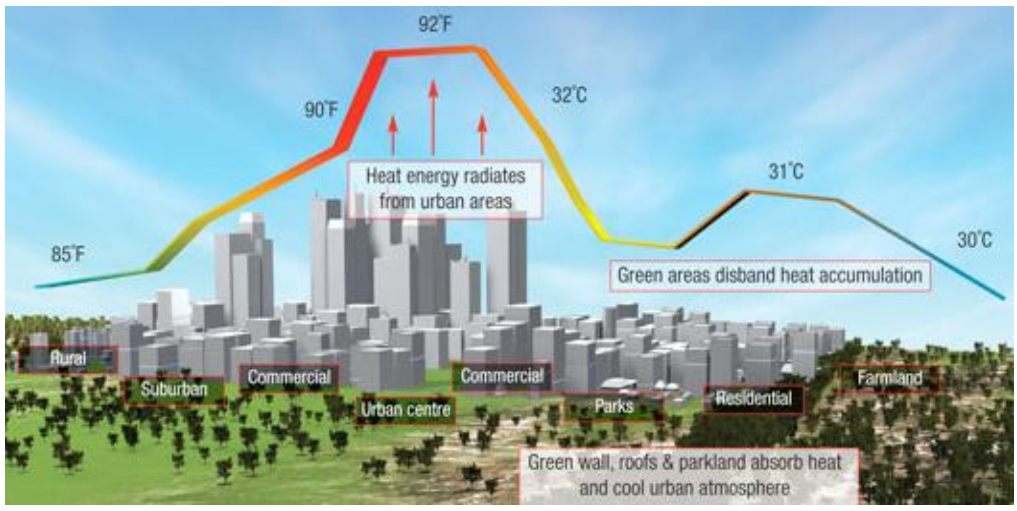

Fig 5. The change of temperature in city and surround (Sources: OUPBlog) 
4. Lowering building energy demands

GI employs the natural elements such as trees and vegetative in its development. These elements' cover can lower ambient urban air temperatures over shading, windbreak, and evapotranspiration (Akbari 2001). As the result, the energy demand to cooling the building is decreasing. Green roofs element use also can keep the temperature inside building at comfortable level that also reduce the energy use for conditioning. It is estimated by Liu et al. (2003) that dense green roof application may reduce the energy demand in the summer by over 75 percent.

5. Improving coastal resiliency

Cities that mainly located in coastal area are the most vulnerable to the impacts ofclimate change. Climate change effect by increasing temperature have brought continued sea level rise, amplified storm surges, and more frequent and intense storms (Fahim et al. 2018). Such disasters have made erosion and frequent flooding affecting urban inhabitants and damage property and infrastructure.

The element of coastal "green infrastructure" can buffer waves, reduce soil erosion, and provide other ecosystem services that can help protect and enhance the resilience of coastal regions (Firas 2016) (fig.6). Coastal green infrastructure has been also demonstrably functions effectively in mitigating damage from climate related disasters (Firas 2016). During Hurricane Katrina, coastal wetlands protected southeastern Louisiana and southern Mississippi by soaking up water that pounded these coastal areas and reducing the inland dispersion of storm surge (Barbier 2013).

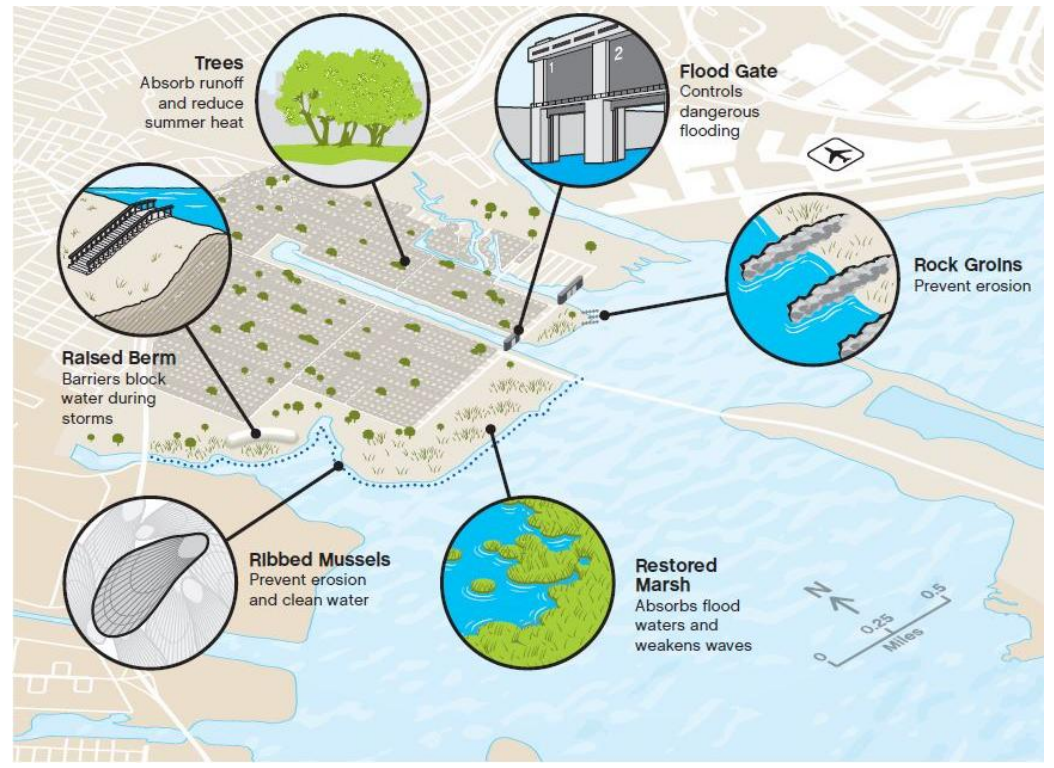

Fig 6. The incorporation of Gray and Green infrastructure in improving coastal resilience (Sources: 3blmedia)

6. Reducing energy needed to manage water

Water city agencies usually use a lot of energy produced by power plants to treat and transport drinking water and wastewater. The introducing of GI into water management system for drinking and wastewater can substantially save the municipal and domestic energy through reducing stormwater flows into sewer systems, recharging aquifers, and conserving water. 
As urban stakeholders continue to employ these recommended strategies at any scales, it is important to identify and leverage the benefit of GI-not only in mitigating the impact of climate related disasters, but also in supporting social and economic development while securing coastal cities healthy and livable to improve urban climate resilience. Urban stakeholders; government and community must consider how to plan and rebuild coastal cities with full participation, in ways that successfully incorporate green and gray infrastructure. They must actively to endeavor to create the sustainable cities that community and future generation deserve.

\section{CONCLUSION}

Coastal areas as the location of cities are center of growth in many countries. Yet, it is argued that these cities have not met the sustainability caused by increasing losses and damages of climate related disasters such as flooding, drought, sea level rise etc. This creates the great pressure to its community challenging the urban resilience capacity. The climate resilience issue in the cities have taken place in the adoption and implementation of urban planning such as green infrastructure/GI development to supplement existing gray infrastructure. This study addresses that the development of GI can benefit cities associated with social, economy and environment. It is recommended that some strategies can be used at any scales (regional, city, neighborhood and site) to improve urban climate resilience. These strategies are managing flood risk, building resiliency to drought, reducing the urban heat island effect, lowering building energy demands, improving coastal resiliency, and reducing energy needed to manage water. The acknowledgement of social and economic benefits of GI is other key issues to secure the success of development for advancing the urban climate resilience.

\section{REFERENCES}

Akbari, H., Pomerantz, M., \& Taha, H. (2001). Cool Surfaces and Shade Trees to Reduce Energy Use and Improve Air Quality in Urban Areas. Solar Energy, 70, 3, 295-310.

Barbier, E. B., Georgiou, I. Y., Enchelmeyer, B., \& Reed, D. J. (2013). The Value of Wetlands in Protecting Southeast Louisiana from Hurricane Storm Surges. PLoS ONE,8(3). doi:10.1371/journal.pone.0058715.

Emmanuel, O., Cassidy, J., \& Donald, B. (2017). The data gap: An analysis of data availability on disaster losses in sub-Saharan African cities. International Journal of Disaster Risk Reduction.26,24-33, https://doi.org/10.1016/j.ijdrr.2017.09.026.

Fahim, N., David, W., Danielle, C., \& David, R. (2018). An investigation of coastal climate change risk assessment practice in Australia. Environmental Science \& Policy. 80,9-20. https://doi.org/10.1016/j.envsci.2017.11.003.

Firas, S., \& Michael, P. (2016). The role of nature-based infrastructure (NBI) in coastal resiliency planning: A literature review. Journal of Environmental Management.183,10881098. https://doi.org/10.1016/j.jenvman.2016.09.077.

Gill, S. E., Handley, J. F., Ennos, A. R., \&Pauleit, S. (2007). Adapting cities for climate change: The role of the green infrastructure. Built Environment, 33(1), 115-133. DOI: 10.2148/benv.33.1.115

IPCC (2012). Managing the Risks of Extreme Events and Disasters to Advance Climate Change Adaptation. Cambridge University Press. Cambridge, 1-502.

IPCC (2014). AR5 - Climate Change 2014 - Impacts, Adaptation and Vulnerability. Cambridge University Press. Cambridge. 59-60.

Klok, L., \&Kluck, J. (2018). Reasons to adapt to urban heat (in the Netherlands). Urban Climate, 23, 342-351. https://doi.org/10.1016/j.uclim.2016.10.005. 
Liu, K. \& Baskaran, B. (2003). Thermal Performance of Green Roofs through Field Evaluation. Greening Rooftops for Sustainable Communities, Chicago.

Matthews, T., Lo, A, \& Byrne, J.A. (2015). Reconceptualizing green infrastructure for climate change adaptation: Barriers to adoption and drivers for uptake by spatial planners. Landsc. Urban Plan. 138, 155-163.

Manyena, S.B. (2006). Rural local authorities and disaster resilience in Zimbabwe. Disaster Preventionand Management, 15, 810-820.

Mark, A., Edward, T., McMahon, Mark, A.(2006).Green Infrastructure: Linking Landscapes and Communities. The Conservation Fund.

Mentens, J., Raes, D., Hermy, M. (2006). Green roofs as a tool for solving the rainwater runoff problem in the urbanized 21st century?.Landscape and urban planning 77 (3), 217-226.

NYC Enviromentl Protection (2018). Rain Barrel Giveaway Program. Available at http://www.nyc.gov/html/dep/html/stormwater/rainbarrel.shtml.

Pelling M (2003) The vulnerability of cities: Natural disasters and social resilience. (London: Earthscan).

Pielke, R. A. (2013). Climate vulnerability: Understanding and addressing threats to essential resources. Amsterdam: Academic Press is an imprint of Elsevier.

Rajashree, K., Aparna, R., Anurag, B.(2018). Urban Heat Island studies in South Asia: A critical review. Urban Climate. https://doi.org/10.1016/j.uclim.2017.12.006.

Rock, B. N., Lynne, C., Walker, H., Bradbury, J., Dingman, S. L., \& Federer, C. A. (2001). Climate impacts on regional water. The New England regional assessment. University of New Hampshire.

Trenberth, K. (2011). Changes in precipitation with climate change. Climate Research, 47(1/2), 123138. http://www.jstor.org/stable/24872346.

UNISDR (2005b). Hyogo Framework for Action 2005-2015: Building the Resilience of Nations and Communities to Disasters. World Conference on Disaster Reduction. 18-22 January 2005, Kobe, Hyogo, Japan. A/CONF.206/6. UNISDR.

UNISDR (2009). Terminology on Disaster Risk Reduction. UNISDR.

US Environmental Protection Agency/ USEPA. (2010). Green infrastructure case studies: Municipal policies for managing stormwater with green infrastructure (EPA-841-F-10e004). Washington, DC: Office of Wetlands, Oceans and Watersheds.

Yosef, J. (2013). Planning the resilient city: concepts and strategies for coping with climate change and environmental risk. Cities, 31,220-229.

HTTPS://DOI.ORG/10.1016/J.CITIES.2012.05.004. 